\title{
Disyllabic post-nominal locatives in Mandarin Chinese*
}

\author{
Pei-Jung Kuo (Chiayi)
}

\begin{abstract}
In this paper, I focus on disyllabic post-nominal locatives in Mandarin Chinese. In the literature, disyllabic post-nominal locatives have traditionally been considered nouns. Recent proposals, however, have offered different analyses. In $\mathrm{Wu}$ (2015), the typical disyllabic post-nominal locative falls somewhere between an adposition and a noun. Djamouri/Paul/Whitman (2013) and Paul (2015) discuss some new disyllabic post-nominal locatives and propose that they are postpositions. In contrast to these analyses, I argue that the commonly analyzed disyllabic postnominal locatives are indeed nouns, and that so too is one subtype of the locatives recently proposed to be postpositions. I further examine this subtype and discuss its unique behavior. Finally, a diachronic study of disyllabic post-nominal locatives indicates that they may not share the same analysis as mono-syllabic post-nominal locatives.
\end{abstract}

\section{Introduction}

In this paper, I would like to examine disyllabic post-nominal locatives in Mandarin Chinese and discuss the relevant findings and implications. The mention of post-nominal locatives typically brings to mind the mono-syllabic variety, like shang ('up'), marked in bold in (1).

(1) Zhangsan [(zai) zuozi shang] fang-le yi-ben shu. Zhangsan at table up put-ASP one-CL book 'Zhangsan put a book on the desk.'

Additional examples include hou ('behind') and li ('inside'), among others. In the literature, the lexical category of this type of locative is quite controversial, but there are three primary kinds of proposals, noted in (2).

(2) a. Postposition: Tai (1973); Peyraube (1980); Ernst (1988); Djamouri/Paul/Whitman (2013); Paul (2015).

b. (Deviated) noun: Chao (1968); Li (1990); McCawley (1992); Huang/Li/Li (2009); Li (2016); Zhang (2017).

c. Clitic: Liu (1998); Zhang (2002); Sun (2008).

\footnotetext{
* This paper is part of my research sponsored by the Ministry of Science and Technology, Taiwan (Grant No. MOST 106-2410-H-415-016). I hereby acknowledge the financial support of the MOST. I would also like to thank the two anonymous reviewers for their valuable comments and suggestions on the previous version of this paper. All errors remain mine.
} 
If one examines the syntactic behaviors of mono-syllabic post-nominal locatives, it is not surprising that it is so difficult to categorize them, because the locative's behavior can be accounted for by all three types of proposal. For example, in (3) the NP preceding the mono-syllabic postnominal locative is not allowed to move to the topic position.

$\begin{array}{llllllll}\text { (3) }{ }^{*} \text { Zuozi }_{i} & \text { Zhangsan } & \text { (zai) } & {\left[\begin{array}{llll}t_{i} & \text { shang }\end{array}\right]} & \text { fang-le } & \text { yi-ben } & \text { shu. } \\ \text { table } & \text { Zhangsan } & \text { at } & & \text { up } & \text { put-ASP } & \text { one-CL book }\end{array}$

'Zhangsan put a book on the table.'

The ungrammaticality of (3) could be explained by the ban on stranding a postposition, similar to the ban on preposition stranding in (4).

(4) a. Lisi [zai fangjian] shuijiao.

Lisi in room sleep.

'Lisi is sleeping in the room.'

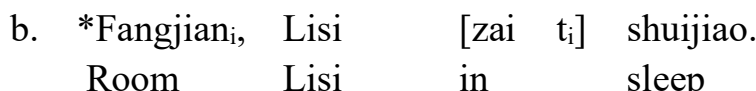

However, it could also be accounted for by the deviated noun proposal, since a deviated noun has different properties from those of a standard noun. Finally, the clitic proposal could also explain the ban on the stranding because clitics cannot stand alone. Because the syntactic behaviors of the mono-syllabic post-nominal locatives are not very salient, it is hard to tease these category analyses apart from each other.

Putting the controversy of the mono-syllabic post-nominal locatives aside, in this paper I would like to focus on several different types of disyllabic post-nominal locative in Chinese that have recently been categorized as adpositions or postpositions. In section 2, I examine both the typical noun-like properties and the non-noun-like properties of the well-known disyllabic postnominal locatives and argue that these locatives cannot be adpositions, contra $\mathrm{Wu}$ (2015). In Section 3, I show that some newly discussed disyllabic post-nominal locatives in Djamouri/Paul/Whitman (2013) and Paul (2015) should be divided into two subtypes because they behave in distinct ways. I argue that one subtype cannot be considered a postposition, but, rather, falls into the category of noun. In Section 4, this noun-like subtype of disyllabic postnominal locative and its unique behaviors are discussed. A diachronic search is also conducted and suggests that Djamouri/Paul/Whitman's (2013) reanalysis proposal and timeline for monosyllabic post-nominal locatives may not be applicable to all disyllabic post-nominal locatives. I conclude this paper in the last section.

\section{The commonly analyzed disyllabic post-nominal locatives}

In this section, I will first examine the properties of the well-known disyllabic post-nominal locatives (henceforth DPL's) and will argue that, while they exhibit both noun-like and nonnoun-like properties, the presence of non-noun-like properties does not necessarily entail that these locatives have to be something other than nouns. They can still be nouns, with their own special noun characteristics. 


\subsection{The noun-like properties}

In this section, the noun-like syntactic behaviors of the well-known (henceforth "commonly analyzed") disyllabic post-nominal locatives will be examined. In the literature, commonly analyzed DPL's have been contrasted with mono-syllabic post-nominal locatives because of their different syntactic behaviors. That is, while the lexical status of mono-syllabic post-nominal locatives remains quite controversial, the commonly analyzed DPL's have been consistently proposed to be nouns. In general, the commonly analyzed DPL's are formed by adding words such as mian ('side'), tou ('head') and bian ('side') to mono-syllabic post-nominal locatives. For example, some typical commonly analyzed DPL's are limian ('inside'), houtou ('back'), waibian ('outside').

There are at least four differences noted in the literature between mono-syllabic post-nominal locatives and commonly analyzed DPL's, and these differences all suggest that the commonly analyzed DPL's are noun-like. The first difference, shown in (5), is that the mono-syllabic postnominal locative cannot stand alone without a preceding location noun in (5a), but this is allowed for both the disyllabic post-nominal locative in (5b) and for the typical noun in $(5 c)$.

$\begin{array}{llll}\text { a. Zhangsan zai *(fangjian) } & \text { li. } & \text { (mono-syllabic) } \\ & \text { Zhangsan in room } & \text { inside } & \\ \text { 'Zhangsan is inside the room.' } & & \\ \text { b. Zhangsan zai (fangjian) } & \text { limian. } & \text { (disyllabic) } \\ & \text { Zhangsan in room } & \text { inside } & \\ & \text { 'Zhangsan is inside (the room).' } & & \\ \text { c. } & & \\ & \text { Zhangsan da-po (jiaoshi) } & \text { chuanghu. } & \text { (typical noun) } \\ & \text { 'Zhangsan break classroom window } & \end{array}$

Secondly, while it is not possible to put the subordinator de ('DE') between the preceding location noun and the mono-syllabic post-nominal locative in (6a), the subordinator is optional between the preceding location noun and the disyllabic post-nominal locative in (6b) and between the two typical nouns in (6c) (cf. Lü 1980).

$\begin{array}{llll}\text { (6) a. Zhangsan zai *(fangjian) } & (* \text { de) } & \text { li. } & \text { (mono-syllabic) } \\ \text { Zhangsan in room } & \mathrm{DE} & \text { inside } & \\ \text { 'Zhangsan is inside the room.' } & & \\ \text { b. Zhangsan zai fangjian (de) } & \text { limian. } & \text { (disyllabic) } \\ & \text { Zhangsan in room DE } & \text { inside } & \\ \text { 'Zhangsan is inside the room.' } & & \\ \text { c. Zhangsan da-po jiaoshi } & \text { (de) chuanghu. } & \text { (typical noun) } \\ & \text { Zhangsan break classroom } & \text { DE window } & \end{array}$

Thirdly, if we apply the coordination test by Liu (1998), the results in (7a) show that coordination of the two mono-syllabic post-nominal locatives is not allowed; however, coordination of the commonly analyzed DPL's in (7b) is allowed, just like for the two typical nouns in (7c).

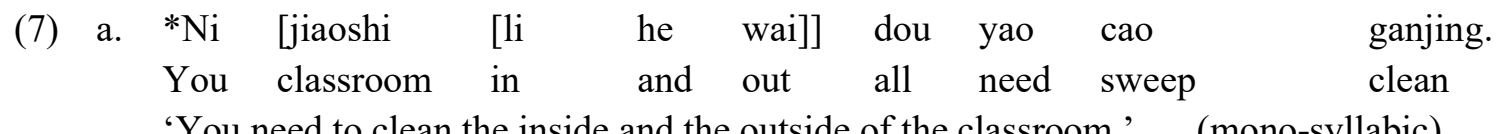



b. Ni [jiaoshi [limian he waimian]] dou yao cao ganjing. You classroom inside and outside all need sweep clean 'You need to clean the inside and the outside of the classroom.' (disyllabic)
c. Ni yao cao [jiaoshi he zoulang]. you need sweep classroom and hallway 'You need to clean the classroom and the hallway.' (typical noun)

Finally, while it is not possible to topicalize the preceding location noun of mono-syllabic postnominal locatives, as shown in (8a). Topicalization is acceptable for the commonly analyzed DPL's in (8b), reflecting the same pattern as typical nouns in (8c) (cf. Huang 1982)
(8) a. *Jiaoshi, ni $\left[\begin{array}{lll}t_{i} & \text { li }\end{array}\right]$ yao cao ganjing. (mono-syllabic) classroom you inside need sweep clean 'You need to clean the inside of the classroom.'
b. Jiaoshi $\mathrm{i}_{\mathrm{i}}$ ni $\left[\begin{array}{lllll}\mathrm{t}_{\mathrm{i}} & \text { limian }\end{array}\right]$ yao cao ganjing. (disyllabic) classroom you inside need sweep clean
'You need to clean the inside of the classroom.'
c. Jiaoshi, ni $\left[t_{i}\right.$ chuanghu $]$ yao ca ganjing. (typical noun) classroom you window need wipe clean
'You need to wipe clean the windows of the classroom.'

From the above comparisons, it would indeed appear that, while the categorical status of monosyllabic post-nominal locatives remains controversial, the noun-like patterning of commonly analyzed DPL's provides evidence for their status as nouns. However, in the following section, additional comparisons between DPL's and nouns from Wu (2015) complicate this picture.

\subsection{The non-noun-like properties}

In this section, I would like to present more comparisons between disyllabic post-nominal locatives and typical nouns in Mandarin Chinese. Although, as previously discussed, the commonly analyzed DPL's show noun-like properties, they can in fact also exhibit non-noun-like properties.

As observed in Wu (2015), commonly analyzed DPL's such as limian ('inside') and waitou ('outside') exhibit some properties that are not shared by typical nouns. First of all, commonly analyzed DPL's cannot be modified by typical adjectives, as shown in (9), but this is perfectly acceptable for typical nouns, as shown in (10).
a. *Zhe-ge fangjian
ganjing this-CL room
clean
de limian
'This clean inside of the room is very bright.'
b. *Zhe-ge huayuan meili de this-CL garden beautiful DE outside
There grow trees in the beautiful outside of this garden.'
a. Zhe-ge ganjing de fangjian hen liang. this-CL clean DE room very bright 'This clean room is very bright.'
b. Zhe-ge meili de huayuan zhong-le shu. this-CL beautiful DE garden plant-ASP tree
'There grow trees in the beautiful garden.'

hen

liang.

zhong-le shu. plant-ASP tree 
Secondly, commonly analyzed DPL's such as limian ('inside') can be modified by a degree modifier, such as zui ('most') in (11a), or a measure phrase, as in (11b). However, this kind of modification is not available for typical nouns, as shown in (12). ${ }^{1}$

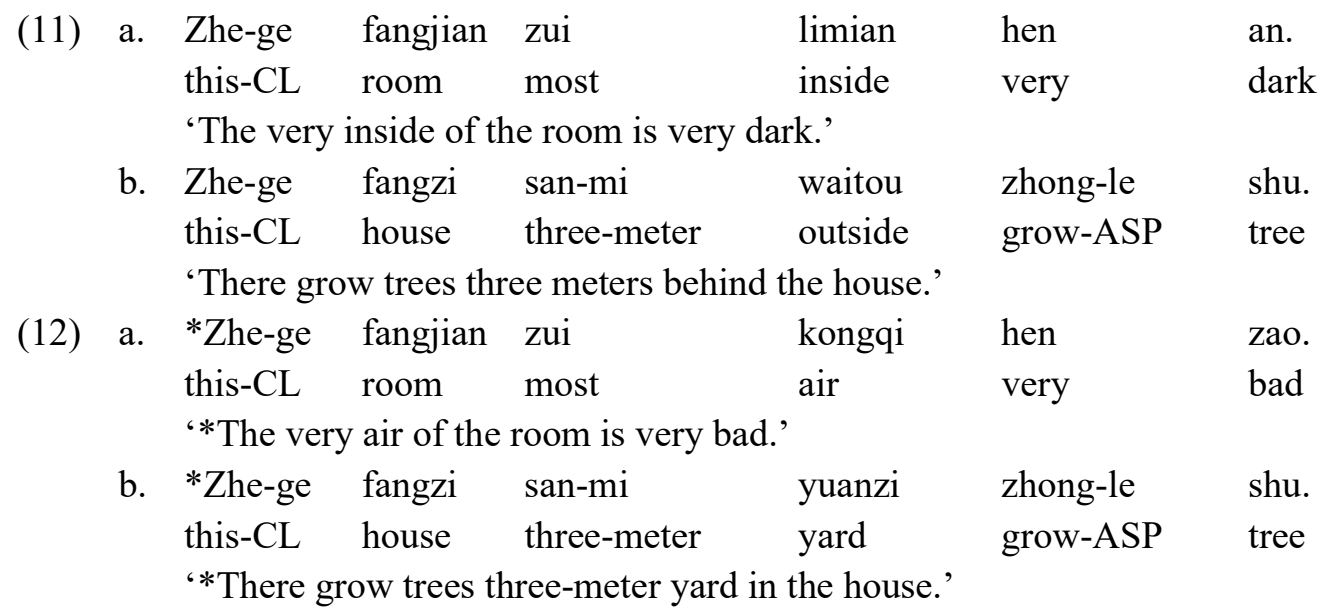

Thirdly, commonly analyzed DPL's cannot be modified by quantifiers such as meige ('every') or yixie ('some'), as in (13), yet this is quite common for typical nouns, as in (14).

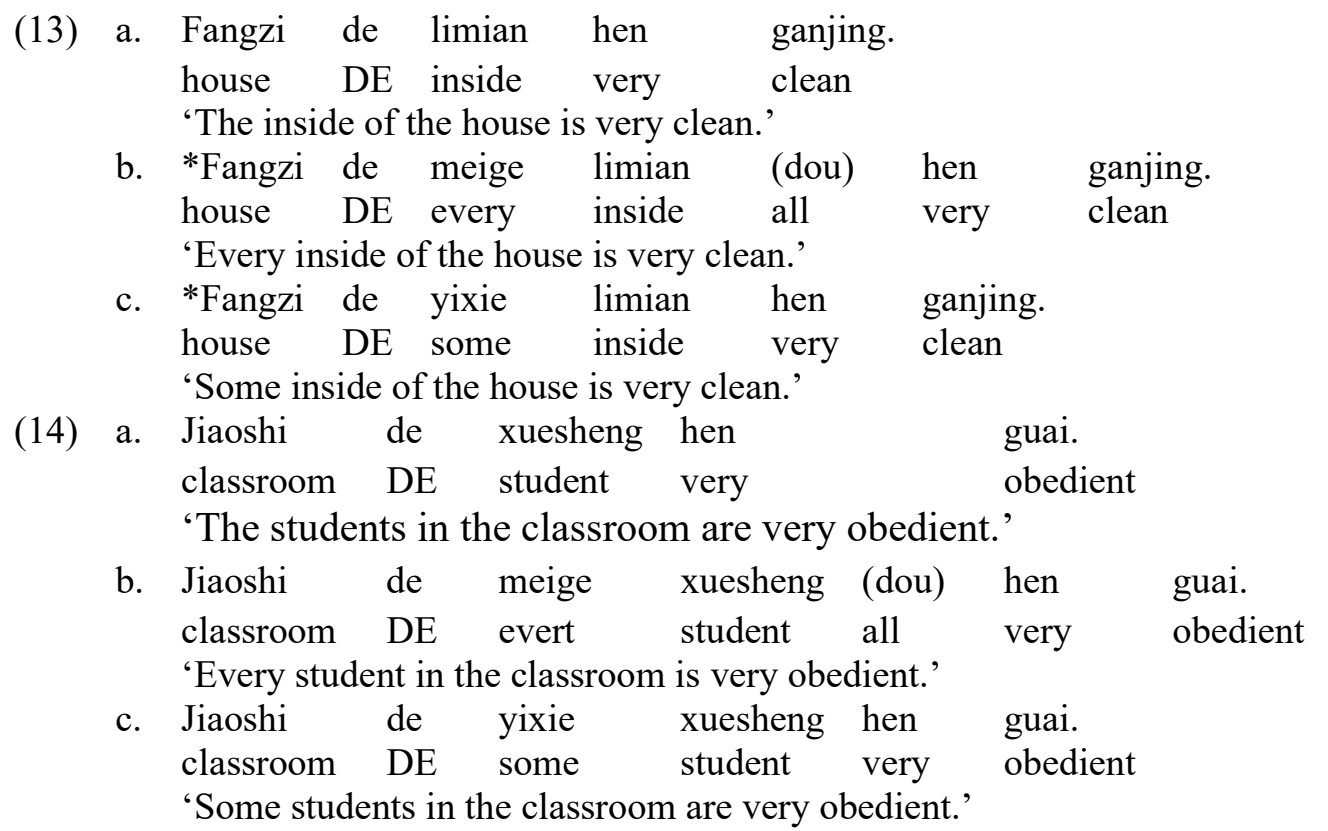

Finally, commonly analyzed DPL's can take a direct argument without a genitive marker, as in (15); however, this is not available for typical nouns, as observed in (16).
(15) Wo ba shu fang zai shugui (de) limian.
I BA book put on bookshelf DE inside
'I put the book inside the bookshelf.'
(16) Wo xihuan Lisi *(de) maozi.
I like Lisi DE hat
'I like Lisi's hat.'

\footnotetext{
${ }^{1}$ As pointed out by one of the reviewers, the acceptance of zui ('most') to modify limian ('inside') may have to do with the partionability and relativity of "insideness".
} 
Based on the above observations and comparisons, Wu (2015) suggests that the categorical status of the commonly analyzed disyllabic post-nominal locative is ambiguous between a noun and an adposition. The above non-noun-like parts are the $\mathrm{P}$ use for these commonly analyzed DPL's. As for the noun-like parts shown in Section 2.1, they will be categorized as the $\mathrm{N}$ use for these commonly analyzed DPL's. ${ }^{2}$

\subsection{Adposition properties?}

In the previous discussion, we have seen that in $\mathrm{Wu}$ (2015), the commonly analyzed DPL's show some non-noun-like properties. Recall that Wu proposes that commonly analyzed DPL's are ambiguous between nouns and adpositions, a proposal which implies that the locatives' non-noun-like properties should be adposition-like. To support her arguments, Wu points out that in the following Dutch example (17) (i. e. de Dikken 2010), the preposition can be modified by a measure phrase.

(17) de river loopt twee meter achter het huis langs

The river goes two meter behind the house along

However, typical prepositions in Mandarin Chinese do not in fact show this property. Indeed, as shown in (19) to (22), when the tests from $\mathrm{Wu}$ (2015) are applied to the typical prepositional phrase in (18), all of the sentences are ungrammatical.

\begin{tabular}{|c|c|}
\hline Zhangsan & \\
\hline
\end{tabular}

'Zhangsan borrowed money from the bank.'

$\begin{array}{lllllll}\text { *Zhangsan } & \text { da } & \text { de } & \text { [cong } & \text { yinghang } & \text { jie } & \text { qian. } \\ \text { Zhangsan } & \text { big } & \text { DE } & \text { from } & \text { bank } & \text { borrow money }\end{array}$

'Zhangsan borrowed money from the big bank.'

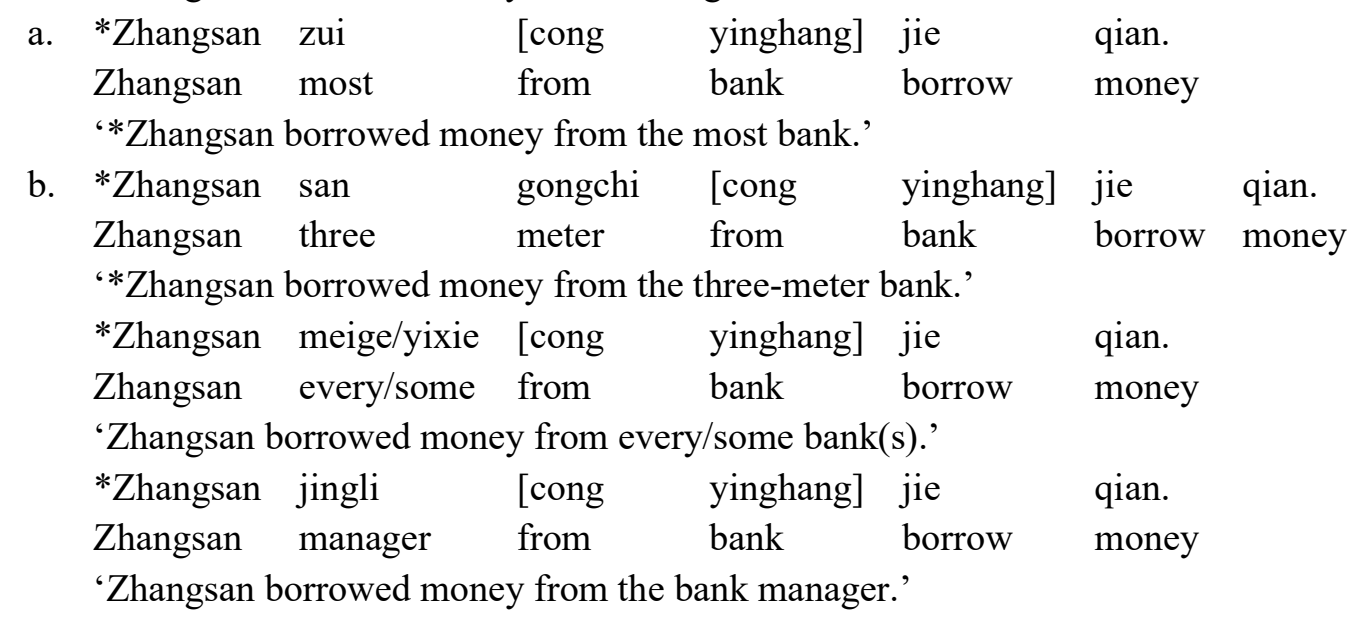

Therefore, while Wu (2015) shows us that commonly analyzed DPL's do not behave like typical nouns in Mandarin Chinese, it does not necessarily follow that they are adpositions.

To further highlight this point, let us examine each of the test results closely to see if there might be other explanations for the locatives' apparent non-noun-like behavior. These unique behaviors might still in fact be explained under the proposal that DPL's are nouns. First of all,

\footnotetext{
${ }^{2}$ More specifically, the $\mathrm{N}$ use refers to the relational noun usage, which is later linked to the "vector space" (cf. Svenonius 2007,2008$)$ by $\mathrm{Wu}(2015)$.
} 
recall that it was shown that commonly analyzed post-nominal locatives cannot be modified by an adjective, as repeated in (23).
a. *Zhe-ge fangiian ganjing de limian hen liang. this-CL room clean DE inside very bright
'This clean inside of the room is very bright.'
b. *Zhe-ge huayuan meili de waitou zhong-le shu. this-CL garden beautiful DE outside plant-ASP tree 'There grow trees in the beautiful outside of this garden.'

Notably however, the commonly analyzed disyllabic locative in (23) and the preceding location NP show a meronym/part-whole relationship. For other NPs that have this kind of meronym/part-whole NP combination, it is also the case that an adjective cannot modify the "part NP" directly. This is illustrated in (24).
(24) a. ?*zhe-jian jiaoshi ganjing de chuanghu this-CL classroom clean DE window 'the clean window of this classroom'
b. ?*zhe-liang chezi youli de luntai this-CL car powerful DE tire 'the powerful tire of this car'

Yet, if jiaoshi ('classroom') and chezi ('car'), the "whole NPs" in the meronym/part-whole relationship, are removed in (23) and (24), adjective modification becomes possible, as shown in(25) and (26). ${ }^{3}$
(25) a. ganjing de limian clean DE inside 'the clean inside.'
(25) b. meili de waitou beautiful DE outside 'the beautiful outside'
(26) a. ganjing de chuanghu clean DE window 'the clean window'
b. youli de luntai powerful DE tire 'the powerful tire'

Moreover, if the adjectives becomes predicative, the ungrammatical (23) and (24) can also become grammatical, as in (27) and (28).
a. Zhe-ge fangjian limian hen ganjing. this-CL room inside very clean
'This inside of the room is very clean.'
b. Zhe-ge huayuan waitou hen meili. this-CL garden outside very beautiful 'The outside of this garden is very beautiful.'

\footnotetext{
${ }^{3}$ As pointed by one of the reviewers, for those who find example (25) best marginal may require some strong contextual support to make them acceptable.
} 
(28) a. Zhe-jian jiaoshi chuanghu hen ganjing this-CL classroom window very clean 'The window of this classroom is very clean.'

b. Zhe-liang chezi luntai hen youli this-CL car tire very powerful

'The tires of this car are very powerful.'

The above contrasts show that commonly analyzed DPL's can have adjectival modification semantically. They just cannot have preceding adjectival modification structurally when there is a "whole NP" preceding the adjective. This restriction can be explained if these meronym/part-whole NPs have special NP internal structure which cannot take preceding adjectival modification.

Secondly, unlike typical nouns, recall that the commonly analyzed DPL's can be preceded by the degree modifier zui ('most') or a measure phrase. Interestingly, in addition to the superlative zui ('most'), the commonly analyzed DPL's can also be modified by another degree modifier hen ('very'), as shown in (29).

(29) Shu wo fang zai hen limian, ni yao jinqu shufang zhao.

Book I put in very inside you need enter study.room find

'I put the book in the very inside of the study room, you need to enter to find it.'

In Mandarin Chinese, when something can be modified by zui ('most') or hen ('very'), the first lexical category that comes to mind is adjective. This is illustrated in (30).

(30) a. Li xiaojie hen piaoliang.

Li Ms. very beautiful

'Ms. Li is very beautiful.'

b. Li xiaojie shi zui piaoliang de laoshi.

$\mathrm{Li}$ Ms. is most beautiful DE teacher

'Ms. Li is the most beautiful teacher.'

Adjectives like the one in (31) can also be modified by a measure phrase. A similar pattern can be observed in English (i. e. five feet tall, Schwarzschild 2005).

(31) Zhangsan you liang-chi gao.

Zhangsan have two-meter tall

'Zhangsan is two-meters tall.'

If one assumes that the commonly analyzed post-nominal locatives are used adjectivally, it could be the case that the head noun in (10), which is modified by these commonly analyzed post-nominal locatives, is omitted, as illustrated in (32).
a. Zhe-ge fangjian zui limian (de difang) hen an. this-CL room most inside DE place very dark
'The very inside of the room is very dark.'
b. Zhe-ge fangzi san-mi waitou (de difang) zhong-le shu. this-CL house three-meter outside DE place grow-ASP tree 'There are trees grown three meters outside the house.'


Although it is not common to see nouns that can also function as adjectives, such cases do exist in Mandarin Chinese (i. e. Liu/Pan/Gu 1996). For example, the noun tongku ('pain') in (33a) can also function as an adjective in (33b).
a. Ni dong wode tongku ma? you understand my pain Q
'Do you understand my pain?'
b. Zhe shi wo zui tongku de huiyi!

this is my most painful DE memory
'This is my most painful memory!'

Thirdly, recall that the commonly analyzed post-nominal locatives cannot be modified by quantifiers (i. e. *every inside of the house). This seems, however, to be a semantic restriction inherent to the locatives themselves. That is, logically, there is only one inside space of a certain object. Similarly, as shown in (34), neither meige ('every') nor yixie ('some') can be used to modify the noun bizi ('nose'), since a normal person has only one nose.

$\begin{array}{lllll}\text { *Zhangsan de meige/yixie bizi dou hen haokan. } \\ \text { Zhangsan DE } & \text { every/some nose all very } & \text { good-looking } \\ \text { 'Zhangsan's every/some nose(s) are very good-looking.' }\end{array}$

Arguably then, it is simply semantically incompatible to use these quantifiers to modify the commonly analyzed disyllabic post-nominal locative limian ('inside'), as in (13b) and (13c).

Finally, although typical nouns cannot take arguments directly, there are some cases in which possible subordination between two nouns without a subordinator occurs. This can be seen from the following examples in (35). Also note that the cases in (35) show a part-whole relationship between the two nouns.
a. Wo ca-le jiaoshi (de) chuanhu.
I wipe-ASP classroom DE window
'I wiped the window of the classroom.'
b. Wo huan-le chezi (de) luntai
I change-ASP car (DE) tires
'I changed the car's tires.'

To sum up, under Wu's four tests, it is true that the commonly analyzed DPL's do not behave like typical nouns. However, we have also seen that the unique properties of DPL's noted under Wu's tests are also observable with special noun meronym/part-whole combinations in Mandarin Chinese or result from the structural or semantic constraints of the commonly analyzed DPL's themselves. Therefore, there is no conclusive evidence that the commonly analyzed DPL's are adpositions, as proposed by $\mathrm{Wu}(2015)$.

\section{$3 \quad$ More disyllabic post-nominal locatives}

In this section, I will examine some new disyllabic post-nominal locatives discussed by Djamouri/Paul/Whitman (2013) and Paul (2015) and will argue that these locatives are complicated and should be divided into subtypes. The syntactic behaviors of one subtype will also be examined and compared to commonly analyzed DPL's. 


\subsection{New locatives}

Djamouri/Paul/Whitman (2013) and Paul (2015) mention some new DPL's different from those commonly analyzedly discussed. Here, I first categorize them into three subtypes by their formation, as shown in (36).

(36) a. qianhou ('front and back/around'), shangxia ('up and down/around'), zuoyou ('left and right/around, about')

b. yihou ('after'), yilai ('since, during'), yinei ('inside'), yiqian ('before'), yishang ('above'), yiwai ('outside'), yixia ('under')

c. zhijian ('between')

For the first subtype in (36a), the DPL's are basically formed by two mono-syllabic post-nominal locatives. The second subtype in (36b) is formed by combining yi- plus a mono-syllabic post-nominal locative. The third subtype has only one component, as in (36c). For ease of discussion, the first subtype will be called a "parallel disyllabic post-nominal locative," while the second subtype will be called a "yi-type disyllabic post-nominal locative."4

Of note, it seems that the different lexical formations of these locatives also correspond to different syntactic behaviors. The parallel disyllabic DPL's exhibit at least three syntactic differences from the yi-type DPL's and zhijian. The differences can be observed clearly by applying the four tests from Section 2.1 that showed the noun-like behavior of disyllabic post-nominal locatives relative to mono-syllabic post-nominal locatives.

First of all, only the parallel DPL's can stand alone without a preceding location noun, as shown in (37a). However, this is not an option for the yi-type DPL's and zhijian, as illustrated in (37b) and $(37 \mathrm{c})$.
a. Zhangsan cao-le
(fangjian)
qianhou.
Zhangsan sweep-ASP
room
front.back
'Zhangsan swept the front and the back of the room.'
b. Zhangsan cao-le
Zhangsan sweep-ASP
*(fangjian)
yinei.
'Zhangsan swept the inside of the room.'
c. Zhangsan cao-le *(fangjian he zoulang) zhijian.
Zhangsan sweep-ASP room and hallway inside
'Zhangsan swept between the room and the hallway.'

Secondly, the subordinator de ('DE') is also optional between the preceding location noun and the parallel disyllabic post-nominal locative, as in (38a). On the other hand, the subordinator de is prohibited for the yi-type DPL's, as in (38b), and zhijian, as in (38c).
a. Zhangsan cao-le
fangjian
(de) qianhou.
Zhangsan in
room
DE front.back
'Zhangsan swept the front and the back of the room.'

\footnotetext{
${ }^{4}$ As pointed out by one of the reviewers, another candidate for the parallel DPL group is liwai ('inside and outside/around). Moreover, one commonality within this group is that they all can be reduplicated into the AABB form.
} 

b. Zhangsan cao-le fangjian (*de) yinei.
Zhangsan sweep-ASP room DE inside
'Zhangsan swept the inside of the room.'
c. Zhangsan cao-le fangjian he zoulang (*de) zhijian.
Zhangsan sweep-ASP room and hallway DE inside
'Zhangsan swept between the room and the hallway.'

Thirdly, applying the coordination test by Liu (1998) reveals that only the parallel DPL's allow coordination of two DPL's, as shown in (39a). The yi-type DPL's in (39b) cannot be coordinated. Note that this test is not applicable to the third subcategorization since there is only one disyllabic post-nominal locative zhijian in this subtype.
a. Ni [jiaoshi [qianhou he zuoyou] dou yao cao ganjing. you classroom front.back and left.right all need clean clean 'You need to clean the four sides of the classroom.'
b. *Ni [jiaoshi [yinei he yiwai]] dou yao cao ganjing. you classroom inside and outside all need clean clean 'You need to clean the inside and the outside of the classroom.'

Lastly, it is possible to topicalize the preceding location noun of the parallel DPL's, as shown in (40a), but this will result in ungrammaticality for yi-type DPL's and zhijian, as shown in (40b) and (40c).

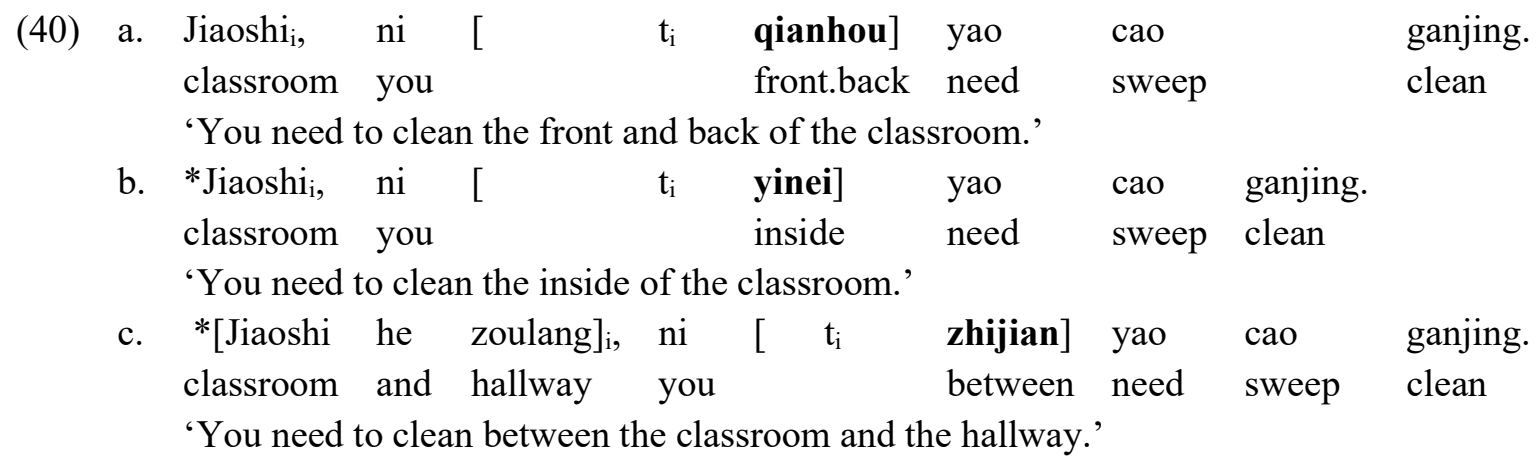

So far, from the above four tests, we can see that, like commonly analyzed DPL's, the parallel DPL's are noun-like, while the $y i$-type DPL's and zhijian pattern with mono-syllabic post-nominal locatives. This patterning seems to imply then that the parallel DPL's are nouns, while the status of the yi-type DPL's and zhijian remains controversial.

If the parallel DPL's are noun-like, as shown above, one might wonder why Djamouri/Paul/Whitman (2013) and Paul (2015) analyze them as postpositions, similar to their analysis for the mono-syllabic post-nominal locatives. The main reason is that Djamouri/Paul/Whitman (2013) do not distinguish the subtypes of DPL's in (36) from each other, and the examples of DPL's in both Djamouri/Paul/Whitman (2013) and Paul (2015) are all yi-type DPL's. Some examples from Paul (ibd.) are cited below as (41) and (42). The location noun cannot undergo relativization, as in (41), or topicalization, as in (42). 
(41)

$\begin{array}{lllllll}\text { *[де [тр [PostP [e] } & \text { yiwai] } & \text { mei } & \text { you } & \text { Zhongguoren } & \text { zhu }] & \text { de }] \\ & \text { beyond } & \text { NEG } & \text { exist } & \text { Chinese } & \text { live } & \text { SUB } \\ \text { nei } & \text { ge } & \text { diqu } & & & & \\ \text { that } & \text { CL } & \text { distinct } & & & & \end{array}$

'*that district where there are not Chinese people living beyond'

(Paul 2015: 104)

$\begin{array}{lllllllll}*[\text { Topp }[ & \text { Nei } & \text { ge } & \text { diqu }] & \text { [TP } & \text { wo } & \text { xiang } & \text { [PostP [e] } & \begin{array}{l}\text { yiwai }] \\ \text { beyond }\end{array} \\ & \text { that } & \text { CL } & \text { district } & & \text { 1SG } & \text { think } & & \\ \text { mei } & \text { you } & \text { xuesheng } & \text { zhu } & & & & & \\ \text { NEG } & \text { exist } & \text { student } & \text { live } & & & & & \end{array}$

'That district, I don't think there are any students living beyond.'

(Paul 2015: 105)

Since yiwai ('beyond') in (41) and (42) belongs to the yi-type DPL's, it would be expected to show a strong relationship with the preceding location noun and could be argued to be a postposition.

However, as mentioned above, because Djamouri/Paul/Whitman (2013) and Paul (2015) generalize from just examples of the $y i$-type locative, their conclusion that DPL's are postpostions needs to be re-evaluated in light of the behavior of parallel DPL's. In the next section, the syntactic behavior of this subtype of locative is examined further, and we assess the evidence so far for the possibility that both the commonly analyzed DPL's and parallel DPL's are in fact nouns.

\subsection{More syntactic behaviors}

In the previous section, it was shown that, like commonly analyzed DPL's, parallel DPL's behave like nouns, whereas yi-type locatives and zhijian exhibit non-noun-like behaviors. However, just as the picture became more complicated in Section 2.2 when the commonly analyzed DPL's were subjected to additional tests from Wu (2015), parallel DPL's subjected to these tests also exhibit more complex patterning. As shown in examples (43) to (46), like commonly analyzed DPL's, but unlike typical nouns, parallel DPL's cannot be modified by preceding adjectives or by quantifiers, and they can take a direct argument without the subordinator de. However, unlike commonly analyzed DPL's, but like nouns, parallel disyllabic post-nominal locatives resist modification by degree/measure phrases.

*Zhe-ge fangjian ganjing de

this-CL room clean DE

'This clean front and back of the room is very bright.'

(44)
a. *Zhe-ge fangjian zui
this-CL room most
qianhou
front.back
'The very inside of the room is very dark.'
b. *Zhe-ge fangjian san-mi qianhou this-CL room three-meter front.back
'The three-meter front and back of the room is very dark.'

$\begin{array}{llllll}\text { *Fangzi } & \text { de } & \text { meige } & \text { qianhou } & \text { (dou) } & \text { hen ganjing. } \\ \text { house } & \text { DE } & \text { every } & \text { front.back } & \text { all } & \text { very clean }\end{array}$

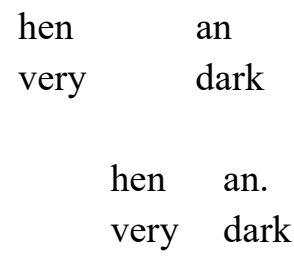
hen ganjing.
very clean

'Every front and back of the house is very clean.' $\begin{array}{lll}\text { qianhou } & \text { hen liang. } \\ \text { front.back } & \text { very } & \text { bright }\end{array}$ 


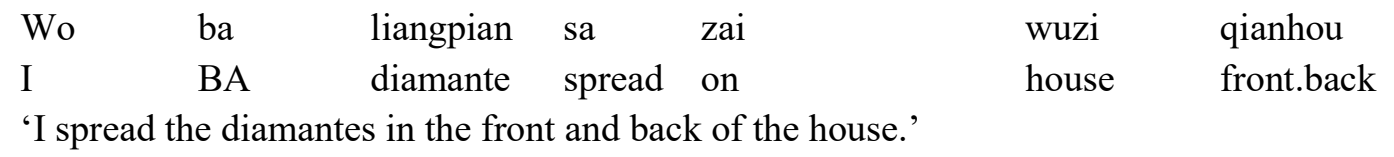

The comparison among typical nouns, commonly analyzed DPL's, and parallel DPL's is summarized in Table 1.

\begin{tabular}{|l|l|l|l|l|}
\hline \multirow{4}{*}{$\begin{array}{l}\text { From the } \\
\text { literature }\end{array}$} & $\begin{array}{l}\text { typical } \\
\text { nouns }\end{array}$ & $\begin{array}{l}\text { commonly } \\
\text { analyzed } \\
\text { DPL's }\end{array}$ & $\begin{array}{l}\text { parallel } \\
\text { DPL's }\end{array}$ \\
\cline { 2 - 5 } & Independent use & $\mathrm{Y}$ & $\mathrm{Y}$ & $\mathrm{Y}$ \\
\cline { 2 - 5 } & DE modifier & $\mathrm{Y}$ & $\mathrm{Y}$ & $\mathrm{Y}$ \\
\cline { 2 - 5 } & Coordination & $\mathrm{Y}$ & $\mathrm{Y}$ & $\mathrm{Y}$ \\
\cline { 2 - 5 } & Topicalization & $\mathrm{Y}$ & $\mathrm{Y}$ & $\mathrm{Y}$ \\
\hline \multirow{3}{*}{$\mathrm{Wu}(2015)$} & Adjective modification & $\mathrm{Y}$ & $\mathrm{N}$ & $\mathrm{N}$ \\
\cline { 2 - 5 } & Degree or measure modifier & $\mathrm{N}$ & $\mathrm{Y}$ & $\mathrm{N}$ \\
\cline { 2 - 5 } & Quantifier restriction & $\mathrm{Y}$ & $\mathrm{N}$ & $\mathrm{N}$ \\
\cline { 2 - 5 } & Taking direct argument & $\mathrm{N}$ & $\mathrm{Y}$ & $\mathrm{Y}$ \\
\hline
\end{tabular}

Table 1 The Comparison

To summarize, we have seen that DPL's have noun-like properties attested in the literature. However, Wu (2015) and Djamouri/Paul/Whitman (2013) and Paul (2015) have argued for the adpositional/postpositional status of the locatives to explain some of their apparent non-nounlike properties. While $\mathrm{Wu}$ shows convincingly that the locatives behave differently in some ways than typical nouns, her argument that they are therefore adpositions is not fully supported. Djamouri/Paul/Whitman (2013) and Paul (2015) argue that the locatives are postpositions, but their analyses seem to be based on just the $y i$-type post-nominal locatives, leaving out examples of parallel post-nominal locatives. We have seen, on the other hand, that some of the supposed non-noun-like behavior of the commonly analyzed DPL's (i. e. disallowing preceding adjectival modification; taking a direct argument without $d e$ ) is in fact similar to that of meronym/part-whole NPs. Other apparent non-noun-like behavior (i. e. disallowing modification by quantifiers) arguably relates to semantic incompatibility, not categorical status. Unlike the $y i$-type locatives, which behave like mono-syllabic post-nominal locatives, parallel DPL's behave much like commonly analyzed DPL's, and, therefore, seem to provide further support for the noun status of both.

Interestingly, the parallel DPL's were shown to have one property similar to typical nouns that commonly analyzed post-nominal locatives did not: they resist modification by degree or measure phrases. For this property, we can infer that, unlike commonly analyzed DPL's, parallel DPL's do not have adjectival counterparts. 


\section{$4 \quad$ More on the parallel disyllabic post-nominal locatives}

In this section, I would like to further examine parallel DPL's for any additional properties distinct from their "commonly analyzed" brethren and consider what the implications are for their categorical status.

\subsection{The preceding NPs}

Since the parallel DPL's are newly discussed members of the group of disyllabic post-nominal locatives, in this section, we further explore some of their unique properties. Indeed, one unique property of the parallel DPL's is that they behave differently when following different types of NPs. In Section 3.2, we saw examples where the parallel DPL's referred to specific locations if preceded by a specific location NP like "the house". However, parallel DPL's can also convey other kinds of meanings. As pointed out by Liu/Pan/Gu (1996), when the DPL's in (36a) follow numeral phrases, temporal phrases, or spatial phrases, they refer to the rough estimation or description of numbers, time, location or range, and so on. Some examples are cited in (47). ${ }^{5}$

$$
\begin{array}{llll}
\text { a. } & \text { sishi } & \text { sui } & \text { shangxia } \\
\text { forty } & \text { year } & \text { around } \\
\text { around forty years' } & \\
\text { b. liang } & \text { dianzhong } & \text { qianhou } \\
\text { two } & \text { o'clock } & \text { around } \\
& \text { 'around two o'clock' } & \\
\text { c. } & \text { changcheng } & \text { neiwai } & \\
& \text { great.wall around } & \\
& \text { 'around the Great Wall' }
\end{array}
$$

The numeral phrase in (47a) and temporal phrase (47b) are both abstract nouns. Hence, it is not surprising that the parallel DPL's do not refer to a specific location in these contexts. There is no literal up/down or front/back sides of age or time. Therefore, the meaning of these parallel DPL's following abstract nouns has been extended to mean "roughly"/“around." However, since changcheng ('the Great Wall') in (47c) is not an abstract noun, one might wonder why the parallel disyllabic post-nominal locative is also interpreted as 'around', but not its literal meaning 'inside and outside' as the other previous parallel DPL's. Note that in previous examples in our discussion, the location noun preceding qianhou was something like jiaoshi ('classroom'), which is a small location NP when compared to changcheng ('the Great Wall'). It is easy for people to identify the front and back parts of a classroom, but it is hard to identify the specific inside or outside of the giant Great Wall. Thus, the size of the preceding location NPs can affect the interpretation of the parallel DPL's. ${ }^{6}$

As mentioned above, when parallel DPL's follow temporal NPs, they are interpreted as "around". Interestingly, when they follow temporal NPs, they also pattern with yi-type DPL's

\footnotetext{
${ }^{5}$ Note that neiwai ('inside and outside/around') is not mentioned in (36) previously. However, according to its components, I still categorize it as a member of the parallel DPL's.

${ }^{6}$ In this paper, when I mention the term "location NP," the default size is a small one, such as a classroom or a living room.
} 
on the tests of nominal status. The application of the four tests from Section 2.1 is shown from (48) to (51).

$\begin{array}{lll}\text { Zhangsan } & * \text { (chuxi) } & \text { qianhou huilai. } \\ \text { Zhangsan } & \text { new.year's.eve } & \text { around } \\ & \text { back }\end{array}$

'Zhangsan will come back around the New Year's Eve.'

\begin{tabular}{|c|c|c|c|c|}
\hline ??Zhangsan & chuxi & de & qianhou & huilai. \\
\hline \multicolumn{5}{|c|}{ 'Zhangsan will come back around the New Year's Eve.' } \\
\hline *Zhangsan & chuxi & [qianhou & he & zuoyou] \\
\hline Zhangsan & new.year's.eve & around & and & around \\
\hline
\end{tabular}

'Zhangsan will come back around the New Year's Eve.'

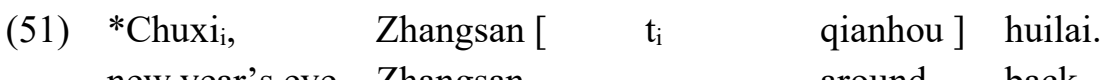
new.year's.eve Zhangsan around back

'Zhangsan will come back around the New Year's Eve.'

Under the four tests, the preceding temporal NP cannot be omitted, as shown in (48); the appearance of the subordinator de is awkward, as shown in (49); the parallel DPL's in (50) cannot be coordinated; and the preceding temporal NP cannot be topicalized in (51). Therefore, it appears that when the preceding NP is a temporal one, the parallel disyllabic post-nominal locative somehow loses its noun-like properties, and behaves like the $y i$-type disyllabic post-nominal locative.

The current discussion hence shows that the properties of parallel DPL's are different depending on the kinds of NPs that precede them. Note that this special property of parallel DPL's is not evident with the commonly analyzed DPL's, since the commonly analyzed DPL's are not compatible with temporal NPs, as shown in (52).

$\begin{array}{llll}\text { *Zhangsan chuxi } & \text { qianmian/litou/waibian } & \text { huilai. } \\ \text { Zhangsan new.year's.eve front/inside/outside } & \text { back } \\ \text { 'Zhangsan will come back before/in/after the New Year's Eve.' } & \end{array}$

While commonly analyzed DPL's can only collocate with location NPs, some of the monosyllabic post-nominal locatives such as qian ('front') and hou ('after') are compatible with temporal NPs, as shown in (53).

$\begin{array}{llll}\begin{array}{l}\text { Zhangsan chuxi } \\ \text { Zhangsan new.year's.eve }\end{array} \text { before/back } & \text { huilai. } \\ \text { 'Zhangsan will come back before/after the New Year's Eve.' }\end{array}$

Thus, it is also expected that when following temporal NPs, mono-syllabic post-nominal locatives should exhibit exactly the same patterns as the parallel DPL's. This expected pattern is shown from (54) to (57).

\begin{tabular}{|c|c|c|c|c|}
\hline Zhangsan & $*($ chuxi) & qian/hou & huilai. & \\
\hline Zhangsan & new.year's.eve & before/back & back & \\
\hline \multicolumn{5}{|c|}{ 'Zhangsan will come back before/after the New Year's Eve.' } \\
\hline *Zhangsan & chuxi & de & qian/hou & huilai. \\
\hline Zhangsan & new.year's.eve & $\mathrm{DE}$ & before/back & back \\
\hline
\end{tabular}


('at') before the location noun. Djamouri/Paul/Whitman (2013) also propose that the semantic content of the preposition $y u$ ('at') has been bleached and has become a light $p$ which can only check Case but not assign a location thematic role. The location thematic role is therefore assigned by zhong which has undergone reanalysis from a location noun, meaning 'the middle', to a postposition meaning 'in'. Hence, semantically, zhong in (59) refers to a general, indeterminate location within the room, not to a specific location like 'the middle/center' of the room.

$\begin{array}{llllllllll}\text { (59) 女子 } & \text { 為 } & \text { 自 } & \text { 殺 } & \text { 於 } & \text { 房 } & \text { 中 } & \text { 者 } & \text { 二 } & \text { 人 } \\ \text { nuzi } & \text { wei } & \text { zi } & \text { sah } & \text { yu } & \text { fang } & \text { zhong } & \text { zhe } & \text { er } & \text { ren } \\ \text { woman } & \text { be } & \text { self } & \text { suicide } & \text { at } & \text { room } & \text { in } & \text { NOM } & \text { two } & \text { person }\end{array}$

'[After the death of their husband], there were two women who killed themselves in their room.'

(Shiji 史記, $1^{\text {th }}$ C. BC)

Thus, under Djamouri/Paul/Whitman's (2013) proposal, the $1^{\text {th }} \mathrm{C}$. BC seems to be the starting point for the reanalysis of post-nominal locatives from location nouns to postpositions. Yet, as mentioned above, the authors only cite specific examples of mono-syllabic post-nominal locatives in the course of their analysis. However, from my search of the texts they examined in the Scripta Sinica database - Shijing, Huainanzi, Guanzi, Yili, and Hanfeizi - this same dividing point does seem to play an important role in the distribution of parallel DPL's like quianhou as well. ${ }^{7}$

Before the $1^{\text {st }} \mathrm{C}$. BC, qianhou can stand alone or precede/follow a VP. For example, it functions as a location noun and combines with another location noun in (60). In (61), it functions as an adjective. In (62), it can be viewed as a subject noun because it precedes a verb. Finally, in (63) it follows a verb and is therefore a complement noun.

(60) 左右 前後, 周而復 所。 zuoyou qianhou zou er fu suo left.right front.back round and return place 'look around and return to your heart'

(Guanzi 管子, chap. $38,1^{\text {st }}$ C. BC)

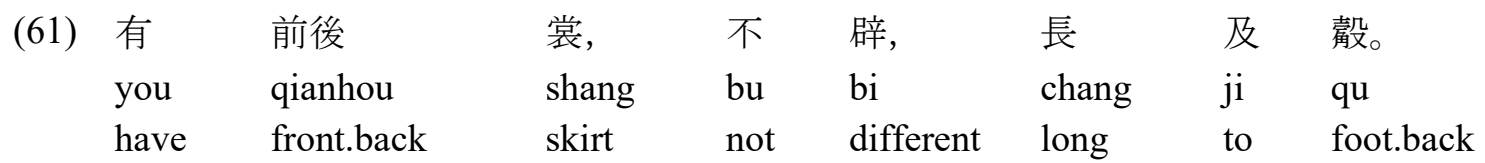
'The skirt is $6 \mathrm{CHI} 6 \mathrm{CUN}$ long in the front, and $8 \mathrm{CHI} 8 \mathrm{CUN}$ long in the back. Its width is the same, and the length has to reach the back of the feet.'

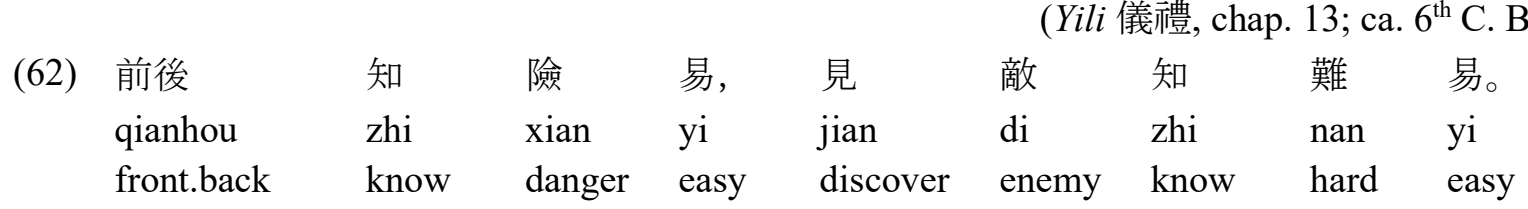
'(The responsibility of Juan Hou) is to clarify whether it is dangerous or safe in the front and the back of the marching army; and whenever the enemy is discovered, he has to figure out whether it is difficult or easy to tackle.'

(Huainanzi 淮南子, chap. $15,2^{\text {nd }}$ C. BC)

\footnotetext{
${ }^{7}$ The Scripta Sinica database is developed by the Sinica Academia from 1984.
} 
(63)

$\begin{array}{lllllll}\text { 心 } & \text { 悁忿 } & \text { 而 } & \text { 不 } & \text { 訾 } & \text { 前後 } & \text { 者, } \\ \text { xin } & \text { juanfen } & \text { er } & \text { bu } & \text { zi } & \text { qianhou } & \text { zhe } \\ \text { mood } & \text { resentful } & \text { and } & \text { not } & \text { look } & \text { front.back } & \text { people } \\ \text { 可 } & \text { 亡 } & \text { 也。 } & & & & \\ \text { ke } & \text { wang } & \text { ye } & & & & \\ \text { will } & \text { come.to.an.end } & \text { YE } & & & & \end{array}$

(Hanfeizi 韓非子, chap. $15,3^{\text {rd }}$ C. BC)

In the above examples, although qianhou does not exhibit the pattern of "NP-zhi-qianhou" at all, in most cases it has the lexical status of noun. However, at this time, qianhou does not ever occur with a temporal NP, and it only has a strictly locational meaning.

After the $1^{\text {th }} \mathrm{C}$. BC, some interesting developments arise. To look for evidence of diachronic change, I focused my search on the genre of historical books in the series of Ershisishi ('Twenty-four Historical Books'), starting with Shiji, a book also examined in Djamouri/Paul/Whitman (2013). ${ }^{8}$ In contrast to the texts before the $1^{\text {st }} \mathrm{C}$. BC, we can find examples where the parallel disyllabic post-nominal locative qianhou immediately follows a location NP, as shown in (64). This is quite similar to what we have in modern Mandarin Chinese.

(64)

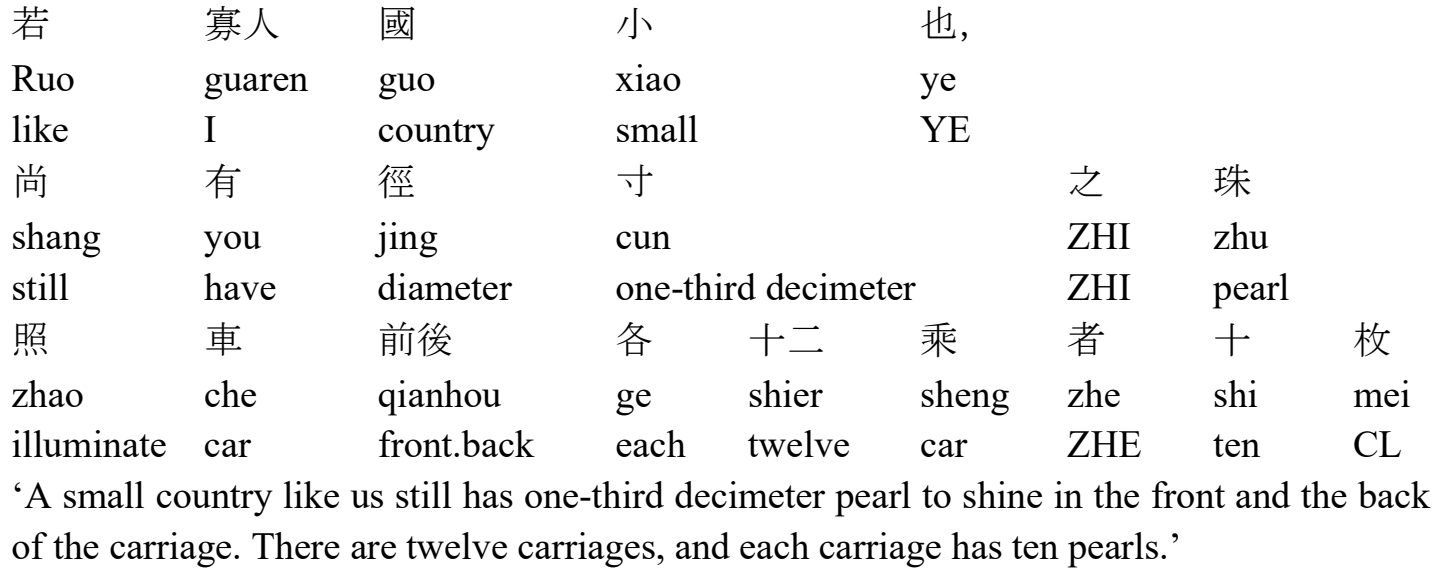

(Shiji 史記, $1^{\text {st }}$ C. BC)

Moreover, we also find examples where qianhou has developed a temporal meaning, referring to a specific span of time. For example, in example (65), qianhou does not refer to a real location, but, rather, to a temporal location, a certain period of time which started right after the first ambassador was forced to stay and which ended when no ambassador was held.

$\begin{array}{lllllllll}\text { 漢 } & \text { 使 } & \text { 留 } & \text { 匈奴 } & \text { 者 } & \text { 前後 } & \text { 十 } & \text { 餘 } & \text { 輩 } \\ \text { Han } & \text { shi } & \text { lu } & \text { Xiongnu } & \text { ZHE } & \text { qianhou } & \text { shi } & \text { yu } & \text { bei } \\ \text { Han } & \text { ambassador } & \text { stay } & \text { Xiongnu } & \text { ZHE } & \text { front.back } & \text { ten } & \text { surplus } & \text { group }\end{array}$

\footnotetext{
${ }^{8}$ In the archaic Scripta Sinica database, I focus on the series of Ershisishi in this corpus. As the name suggests, there are 24 historical books in the database, ranging from around $108 \mathrm{BC}$ to AD 1927. This series is adopted in order to have the same genre synchronically. Since the Scripta Sinica database is an electronic corpus, I simply used the parallel disyllabic post-nominal locatives as keywords to search out their occurrence in Ershisishi. The paraphrases are taken from ErShisishi Quan Yi (The total translation for the twenty-four historical books) by $\mathrm{Xu} / \mathrm{An}(2004)$.
} 
'There are more than ten groups of people during the period when the Han ambassadors were forced to stay in Xiongnu.'

(Shiji 史記, $1^{\text {st }}$ C. BC)

Similarly, in example (66), the parallel disyllabic post-nominal locative qianhou modifies a covert temporal NP, since the interpretation in context suggests that the country Zhao lost four hundred and fifty thousand soldiers during the battle with the Qin country.

$\begin{array}{lllllll}\text { 趙 } & \text { 前後 } & \text { 所 } & \text { 亡 } & \text { 凡 } & \text { 四十五 } & \text { 萬 } \\ \text { Zhao } & \text { qianhou } & \text { suo } & \text { wang } & \text { fan } & \text { sishiwu } & \text { wan } \\ \text { Zhao } & \text { front.back } & \text { SUO } & \text { die } & \text { total } & \text { forty-five } & \text { ten-thousand }\end{array}$

'The Zhao country lost four hundred and fifty thousand soldiers during (the battle with the Qin country).'

(Shiji 史記, $1^{\text {st }}$ C. BC)

In Shiji, then, we see examples where quianhou immediately follows a location noun and refers to a location. We also see instances where it has started to develop a new kind of usage, which is to describe a certain period of time.

In the next historical book Hanshu, which was completed around AD 80, the temporal usage is quite similar to what we find in Shiji. That is, qianhou is to be used to modify a period of time, which is denoted by a clause, as shown from (67) to (69). ${ }^{9}$

$\begin{array}{lllllll}\text { 居 } & \text { 列 } & \text { 大夫官 } & \text { 前後 } & \text { 三十 } & \text { 餘 } & \text { 年, } \\ \mathrm{Ju} & \text { lie } & \text { dafuguan } & \text { qianhou } & \text { sanshi } & \text { yu } & \text { nian } \\ \text { place } & \text { list } & \text { high-ranking.officer } & \text { front.back } & \text { thirty } & \text { surplus } & \text { year } \\ \text { 年 } & \text { 七十二 } & \text { 卒。 } & & & \\ \text { nian } & \text { qishier } & \mathrm{zu} & & & \\ \text { year } & \text { seventy-two } & \text { die } & & & \\ \text { '(Someone) is a high-ranking officer for more than thirty years, and dies at } 72 \text { years old' }\end{array}$

(68) 光 秉政前後云十 年

Guang bingzheng qianhou ershi nian

Guang in.charge front.back twenty year

'Huo Guang was in charge of politics for twenty years.'

(69)

$\begin{array}{lllll}\text { 居 } & \text { 爪丿牙官 } & \text { 前後 } & \text { 十 } & \text { 年 } \\ \text { ju } & \text { zhuayaguan } & \text { qianhou } & \text { shi } & \text { nian } \\ \text { place } & \text { low-ranking.officer } & \text { front.back } & \text { ten } & \text { year }\end{array}$

'(Someone) is a low-ranking officer for ten years'

(Han Shu 漢書, AD 80)

The first use of the parallel disyllabic post-nominal locative qianhou following a temporal NP is found in Houhanshu, as illustrated in (70). In this example, the parallel disyllabic post-nominal locative qianhou refers to the days preceding the first day of the lunar month and the days following it.
(70) 立春
前後
Lichun
qianhou
the.first.solar.term.of.the.lunar.calendar
front.back

\footnotetext{
${ }^{9}$ The missing subject in the clause can be inferred from the preceding texts.
} 


$\begin{array}{lllll}\text { 溫 } & \text { 氣 } & \text { 應 } & \text { 節 } & \text { 者, } \\ \text { wen } & \text { qi } & \text { ying } & \text { jie } & \text { zhe } \\ \text { temperature } & \text { weather } & \text { correspond } & \text { season } & \text { ZHE } \\ \text { 詔令 } & \text { 寬 } & \text { 也。 } & & \\ \text { zhaoling } & \text { kuan } & \text { ye } & \text { YE } & \\ \text { government.order } & \text { loose } & \text { The reason why the temperature and weather match the season around the first solar term of } \\ \text { 'The lunar calendar is because the government's order is loose.' }\end{array}$

(Hou Han Shu 後漢書, AD 445)

From the above diachronic searches, we can see that the $1{ }^{\text {st }} \mathrm{C}$. $\mathrm{BC}$ is indeed a dividing point for the two different kinds of meanings of the parallel disyllabic post-nominal locative qianhou. Before the $1^{\text {st }} \mathrm{C}$. BC, only the location use of qianhou can be found. After that, both its location use, similar to that found before the $1^{\text {st }} \mathrm{C}$. $\mathrm{BC}$, and the temporal uses are present. Further, the development of qianhou's different meanings also corresponds to different syntactic structures. Structurally, the temporal use of quianhou that refers to a circumscribed period of time first appears after a clause. Later, it can follow an NP directly and means "around." These developments are summarized in Figure 1.

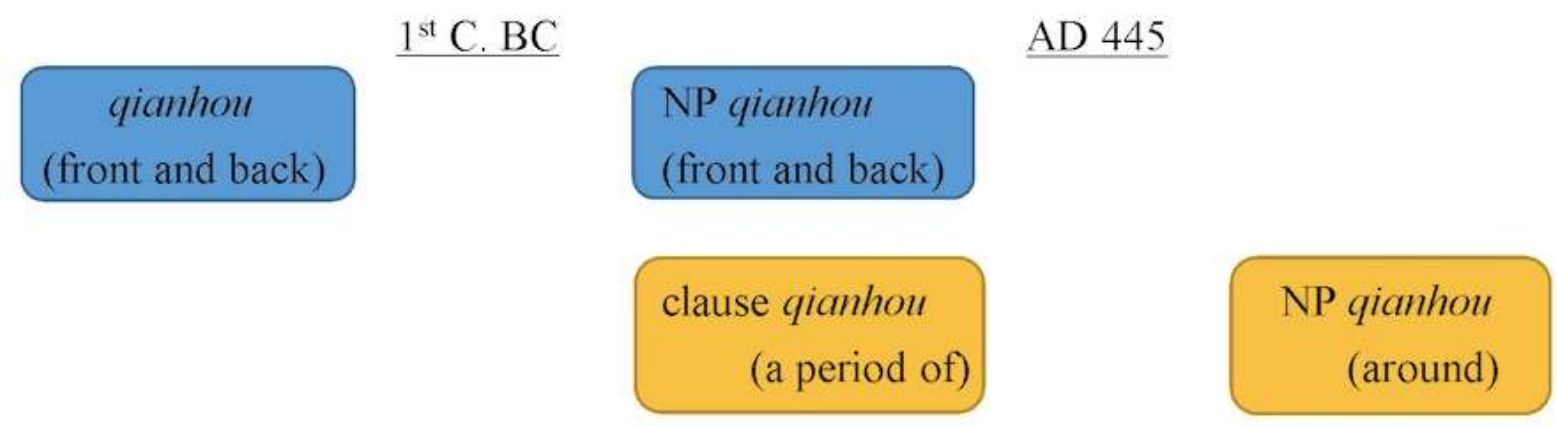

Figure 1 The development of qianhou

In the blue track, qianhou starts out as a location noun before the $1^{\text {st }} \mathrm{C} . \mathrm{BC}$ and continues as a noun after the $1^{\text {st }} \mathrm{C}$. $\mathrm{BC}$ when preceded by a location noun. In the yellow track, if qianhou follows a clause, it could arguably be a relativized NP. Later, it is reanalyzed as a postposition after AD 445. Thus, even if reanalysis of the parallel DPL's is occurring, it has to happen much later than the timeframe proposed by Djamouri/Paul/Whitman (2013). The current examination of parallel DPL's therefore suggests that Djamouri/Paul/Whitman's (2013) proposal for the reanalysis of mono-syllabic post-nominal locatives can not necessarily be applied to parallel DPL's, at least not to qianhou.

\section{Conclusion}

In this paper, I have investigated disyllabic post-nominal locatives in Mandarin Chinese. Although Wu (2015) suggests that commonly analyzed DPL's such as limian ('inside'), houtou ('back'), and waibian ('outside') fall somewhere between an adposition and a noun, I have argued that they should be considered nouns. In addition, I have examined some new DPL's that Djamouri/Paul/Whitman (2013) and Paul (2015) categorize as postpositions and have suggested that one subtype of these locatives, which I call "parallel DPL's," are also nouns, when following location nouns. Further exploration of this subtype revealed that it can have different 
properties when following different types of NPs. Finally, the current diachronic study of quianhou, a parallel disyllabic post-nominal locative, suggests that Djamouri/Paul/Whitman's (2013) reanalysis proposal for mono-syllabic post-nominal locatives may not be applicable to the new DPL's, at least not to the parallel DPL's.

\section{References}

Chao, Yuen Ren (1968): A Grammar of Spoken Chinese. Berkeley: University of California Press.

De Dikken, Marcel (2010): "On the functional structure of locatie and directional PPs". In: Cinque, Guglielmo/Rizzi Luigi (eds.): Mapping Spatial PPs. Oxford, Oxford University Press: 74-126.

Djamouri, Redouane/Paul, Waltraud/Whitman, John (2013): "Postpositions vs. prepositions in Mandarin Chinese: The articulation of disharmony". In: Biberauer, Theresa/Sheehan, Michelle (eds.): Theoretical approaches to disharmony word order. Oxford, Oxford University Press: 74-105.

Ernst, Thomas (1988): “Chinese postpositions - Again”. Journal of Chinese Linguistics 16/2: 219-244.

Huang, C.-T. James (1982): Logical Relations in Chinese and the Theory of Grammar. Ph. D. Dissertation. MIT: Cambridge, MA.

Huang, C.-T. James/Li, Y.-H. Audrey /Li, Yafei (2009): The Syntax of Chinese. Cambridge: Cambridge University Press.

Li, Yen-hui Audrey (1990): Order and constituency in Mandarin Chinese. Dordrecht: Kluwer.

Li, Yen-hui Audrey (2016): "Review article of Waltraud Paul's New Perspectives on Chinese Syntax (2015)". Glossa: a journal of general linguistics 1/1: 1-17.

Liu, Feng-his (1998): “A clitic analysis of locative particles”. Journal of Chinese Linguistics 26/1: 48-70.

Liu, Yuehua/Pan, Wenyu/Gu, Ye. (1996): Shiyong xiandai hanyu yufa [Modern Chinese Grammar]. Taipei: Shida Shuyuan.

Lü, Shuxiang (ed.) (1980): Xiandai hanyu babaici [Eight hundred words of modern Mandarin]. Beijing: Shangwu.

McCawley, James David (1992): "Justifying part-of-speech assignments in Mandarin Chinese". Journal of Chinese Linguistics 20/2: 211-245.

Paul, Waltraud (2015): New Perspectives on Chinese Syntax. Berlin: de Gruyter.

Peyraube, Alain (1980): Les constructions locatives en Chinois modern. Paris: Edition Language Croises.

Schwarzschild, Roger (2005): "Measure phrases as modifiers of adjectives". Recherches Linguistiques de Vincennes 34: 207-228.

Sun, Chaofen (2008): "Two conditions and grammaticalization of the Chinese locative". In: Xu, Dan (ed.): Space in Languages of China: Perspectives Cross-linguistic, Synchronic and Diachronic. Paris, Springer: 199-227.

Svenonius, Peter (2007): “Adpositions, Particles, and the Arguments They Introduce”. In: Reuland Eric J./Bhattacharya, Tanmoy/Spathas, Giogros (eds.): Argument Strutrue. Amsterdam/Philadelphia, Benjamins: 63-103. 
Svenonius, Peter (2008): “Projections of P”. In: Asbury, Anna et al. (eds.): Syntax and Semantics of Spatial P. Amsterdam/Philadelphia, Benjamins: 63-84.

Tai, James (1973): "Chinese as an SOV Language". In: Corum, Claudia/Smith-Stark, T. Cedric (eds): Paper from the $9^{\text {th }}$ Chicago Linguistic Society. Chicago, CLIS: 65-671.

The Scripta Sinica database: hanchi.ihp.sinica.edu.tw/ihp/hanji.htm [22.11.2021].

Wu, Hsiao-Hung Iris (2015): "The Fine structure of Spatial PPs in Mandarin Chinese". In: Tsai, Wei-Tien Dylan (ed): The Cartography of Chinese Syntax. Oxford, Oxford University Press: 209-234.

Xu, Jialu/An, Pingqiu (eds.) (2004): ErShisishi Quan Yi [The total translation for the twentyfour historical books]. Shanghai: Hanyu Da Cidian.

Zhang, Niina Ning (2002): "Movement within a spatial phrase". In: Cuyckens, Hubert/Radden, Gunther (eds.): Perspectives on Prepositions. Tubingen, Niemeyer: 47-63.

Zhang, Niina Ning (2017): “Adpositions". In: Sybesma, Rint et al. (eds.): Encyclopedia of Chinese Language and Linguistics. Vol. 1. Leiden, Brill: 116-122. 